\title{
Applications of High-voltage Resistor Based on Saline Solution in High-voltage Impulse Generation and Measurement
}

\author{
Punyavee Chaisiri and Peerawut Yutthagowith ${ }^{*}$ \\ Faculty of Engineering, King Mongkut's Institute of Technology Ladkrabang, \\ 1 Soi Chalongkrung 1, Ladkrabang, Bangkok, 10520 Thailand \\ (Received June 28, 2019; accepted December 6, 2019)
}

Keywords: saline solution, electrical resistivity, relative permittivity, high-voltage resistor, voltage divider

This paper presents applications of high-voltage (HV) resistors based on saline solution for HV impulse generation and measurement. The electrical resistivity and relative permittivity of saline solution in the frequency range from $100 \mathrm{~Hz}$ to $100 \mathrm{MHz}$ were investigated. The electrical resistivity and relative permittivity were calculated from experimental measurements of the resistance and capacitance of saline solution in a test cell. From the characteristics and the experimental results, the technical data of saline solution with various concentrations of substances were utilized in the design of $\mathrm{HV}$ resistors for $\mathrm{HV}$ impulse generation and measurement, as a current-limiting resistor and an HV resistor used in an HV part of a voltage divider. Moreover, the developed HV resistors were tested to confirm their effectiveness in HV generation and measurement. From the experimental results, it was found that the developed HV resistors have promising characteristics for practical HV impulse generation and measurement. According to the results of this study, an HV resistor based on saline solution has strong potential for application in HV impulse generation and measurement compared with a conventional voltage divider.

\section{Introduction}

Although electrical power equipment generally operates with the system voltage at normal levels, overvoltages occur as a result of switching operation and lightning strikes to the system. Therefore, high-voltage (HV) testing in accordance with international standards is required to confirm the insulation performance of electrical power equipment before its installation in systems. In the HV tests, an HV is generated from sources and applied to such equipment. The vital requirement of the components used in HV generation and measuring systems is high insulation performance. To fulfill this requirement, the components must be insulated. Liquid and gas insulation materials, i.e., mineral oil, synthetic esters, $\mathrm{SF}_{6}$, and $\mathrm{CO}_{2}$, are generally used as the insulation of such components.

*Corresponding author: e-mail: peerawut.yu@kmitl.ac.th

https://doi.org/10.18494/SAM.2020.2528 
The most commonly used liquid insulation material is mineral oil, which has a good insulation characteristic. However, the supply of its raw materials is unstable and its decay may take up to 1000 years, ${ }^{(1)}$ adversely affecting the environment when leakage and contamination occur. $\mathrm{SF}_{6}$ gas has an excellent insulation characteristic, has robustness to high voltages, is non-toxic and non-flammable, and has good heat transfer. However, $\mathrm{SF}_{6}$ contributes to the greenhouse effect and remains in the atmosphere for 1278 years. ${ }^{(2)}$

In addition, $\mathrm{HV}$ impulse generation is required to simulate the overvoltage waveform due to the switching operation and the effect of lightning in the system. According to IEC 60060-1, ${ }^{(3)}$ the standard lightning voltage waveform has a front time $\left(T_{1}\right)$ of $1.2 \mu \mathrm{s}$ and a time to half of $50 \mu \mathrm{s}$. Moreover, some voltage waveforms complying with IEC standards ${ }^{(3,4)}$ have a very short rise time. For example, in the voltage withstand test of insulators, the steep-front voltage waveform ${ }^{(4)}$ has a time to peak of $100 \mathrm{~ns}$ order. Owing to the short rise time of the $\mathrm{HV}$ impulse, the components used for HV generation and HV measuring systems must have good characteristics in a wide frequency range. This background has led to the development of several HV measurement technologies. ${ }^{(5-7)}$ In the past, the design and construction of fast-response measuring systems have encountered many problems. According to the IEC standards, ${ }^{(3,8)}$ the time response of the measuring system should be in the range of $0-10 \mathrm{~ns}$. In the measurement of a voltage with such a short rise time, stray capacitance and undesired inductance in the test circuit significantly affect the accuracy of HV measurement. ${ }^{(9)}$ Therefore, non-inductive components are required for HV generation and measuring systems. Normally, $\mathrm{HV}$ and non-inductive resistors are made of ceramic materials and are insulated with mineral oil and/or $\mathrm{SF}_{6}{ }^{(10)}$ The cost of such components is also high. Moreover, damaged and unused components are difficult to dispose of, causing environmental problems.

To resolve these issues, the development of an $\mathrm{HV}$ resistor using a solution such as $\mathrm{CuSO}_{4}$ or saline solution is an attractive approach owing to the lack of need for mineral oil or an insulating gas. ${ }^{(11-15)}$ The advantages of using such a solution for the development of HV resistors are a simple design, easy construction, and cost-effectiveness. Also, such a solution can withstand high voltages, can be used in a wide frequency range, and has high energy absorption. ${ }^{(15-17)}$ The stray capacitance and stray inductance of HV equipment with a solution as the resistor can easily be controlled by a suitable design of its dimensions and configuration. ${ }^{(14)}$ In terms of environmental concerns, such a solution rapidly decays and is non-toxic. Hence, the development of HV resistors based on saline solution should be investigated.

In this paper, we propose the use of saline solution in the development of HV resistors for $\mathrm{HV}$ impulse generation and measurement. The electrical resistivity and relative permittivity of saline solution in the frequency range from $100 \mathrm{~Hz}$ to $100 \mathrm{MHz}$ were studied. Using a simple equivalent circuit, the electrical resistivity and relative permittivity were extracted and calculated from experimental measurements of the resistance and capacitance of saline solution in a test cell. From the obtained electrical characteristics, the appropriate mixture of deionized water and normal saline can be selected for the design of HV resistors. Two HV resistors were designed for use as a current-limiting resistor in an HV impulse generator and an HV part of a voltage divider in an HV impulse-measuring system. The practicality of the developed components was validated by performing various experiments in an HV laboratory. 
It was found that the developed HV resistors have promising characteristics for $\mathrm{HV}$ impulse generation and measurement. According to the results of this study, the HV resistor based on saline solution has strong potential for application in HV impulse generation and measurement compared with a conventional voltage divider.

\section{Saline Solution}

Saline solution can be used in HV devices owing to its many attractive characteristics. From a chemical viewpoint, saline solution does not cause the corrosion of aluminum or copper conductors, which are important components of HV devices. From a mechanical viewpoint, the large surface area and high volume of saline solution can improve heat transfer when a large current flows. When saline solution is employed in an impulse generator or impulse voltage divider, its electrical characteristics such as resistivity and relative permittivity must be taken into account. We investigated the electrical resistivity and relative permittivity in the frequency range of $100 \mathrm{~Hz}$ to $100 \mathrm{MHz}$ as reported this section. Note that this frequency range covers the application frequencies in HV generation and measurement.

\subsection{Electrical characteristics of saline solution}

Electrical resistivity is an intrinsic property that quantifies how strongly a given material opposes the flow of electric current. ${ }^{(18)}$ A material with low resistivity readily allows the movement of electric charge. For a resistor made of a specified material having a uniform cross section, when an electric current flows though this resistor, its electrical resistivity can be defined as

$$
R=\rho \frac{l}{A},
$$

where $R$ is the electrical resistance of the resistor, $\rho$ is the electrical resistivity $(\Omega \cdot \mathrm{m}), l$ is the length of the resistor (m), and $A$ is the cross-sectional area of the resistor $\left(\mathrm{m}^{2}\right)$.

Generally, the relative permittivity of a material is defined as the ratio of the capacitance $C$ (farad) of a given configuration of the electrode with a specific material as a dielectric to the capacitance $C_{0}$ (farad) with the same configuration with vacuum as the dielectric. ${ }^{(18)}$ Relative permittivity is typically denoted by $\varepsilon_{r}$ and is defined as

$$
\varepsilon=\varepsilon_{0} \varepsilon_{r}=\varepsilon_{0}\left(\varepsilon_{r}^{\prime}+\varepsilon_{r}^{\prime \prime}\right)
$$

where $\varepsilon$ is the complex frequency-dependent absolute permittivity of the material, $\varepsilon_{0}$ is the vacuum permittivity of $8.854 \times 10^{-12} \mathrm{~F} / \mathrm{m}, \varepsilon_{r}^{\prime}$ is the real part of the complex permittivity associated with the stored energy in the material, and $\varepsilon_{r}^{\prime \prime}$ is the imaginary part of the complex permittivity related to the dielectric loss of the material. The relative permittivity is therefore related to the capacitance of a material. The capacitance of a material can be defined as 


$$
C=\frac{\varepsilon A}{d},
$$

where $A$ is the area of two plates $\left(\mathrm{m}^{2}\right), d$ is the distance between the plates (m), and $\varepsilon$ is the permittivity of the material.

\subsection{Experimental setup}

In this study, saline solution was loaded into a test cell. To avoid the effect of the inherent conductivity of the test cell, acrylic glass was used to construct the test cell. It is also a chemically inert material, which is appropriate for this experiment. The dimensions of the test cell were $10 \mathrm{~cm} \times 10 \mathrm{~cm} \times 10 \mathrm{~cm}$. The test cell had two copper electrodes as shown in Fig. 1(a). The size of each electrode was fixed at $10 \mathrm{~cm} \times 10 \mathrm{~cm}$.

In this study, normal saline or saline $0.9(9 \mathrm{~g} \mathrm{NaCl}$ in $1 \mathrm{~L}$ water) was mixed with deionized water to ensure a consistent $\mathrm{NaCl}$ concentration. The deionized water had high resistance and high purity. The normal saline and deionized water are shown in Figs. 1(b) and 1(c), respectively.

The experimental setup is shown in Fig. 1(d). The tested solution was placed in a test cell connected to an impedance analyzer to measure the magnitude $(Z)$ and phase $(\theta)$ in the frequency range from $100 \mathrm{~Hz}$ to $100 \mathrm{MHz}$. From the measured data, the electrical resistivity and relative permittivity were then calculated for the equivalent circuit model.

In this study, a simple equivalent circuit composed of a resistor in parallel with a capacitor was employed. An inductance of $0.3086 \mu \mathrm{H}$ was observed from the current loop of the experimental setup. Therefore, an additional inductor was added to the former equivalent circuit as illustrated in Fig. 2.

\subsection{Test procedure and results}

In this study, $1000 \mathrm{~cm}^{3}$ of deionized water was mixed with various normal saline volumes of 10 to $1000 \mathrm{~cm}^{3}$. These solutions were placed in the test cell and their impedances were measured using an impedance analyzer at frequencies from $100 \mathrm{~Hz}$ to $100 \mathrm{MHz}$. The electrical

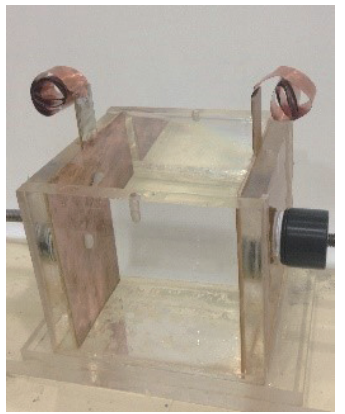

(a)

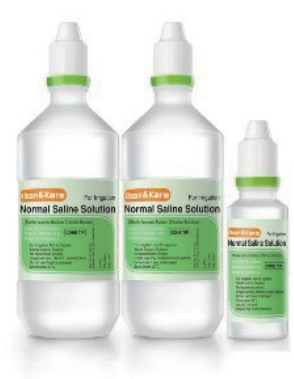

(b)

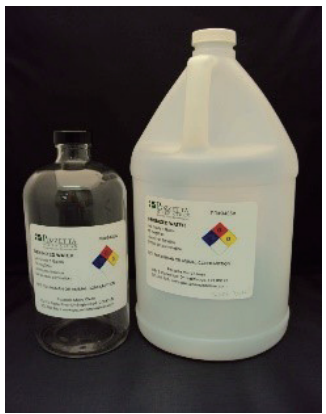

(c)

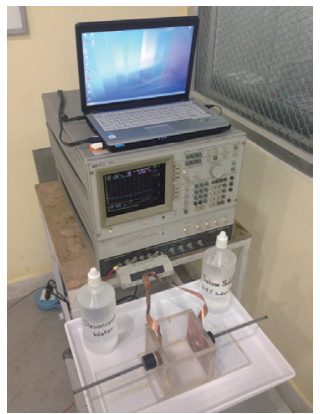

(d)

Fig. 1. (Color online) (a) Test cell developed for studying the electrical characteristics of the experimental liquid, (b) saline solution, (c) deionized water, and (d) setup of test cell and instrument in the experiment. 


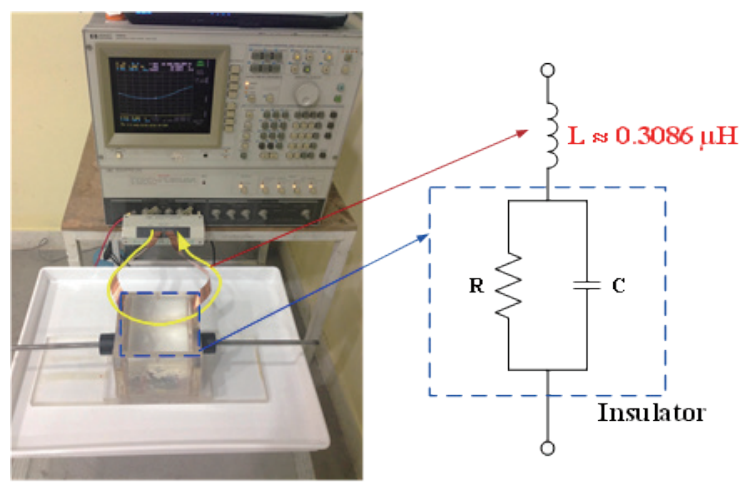

Fig. 2. (Color online) Proposed equivalent circuit model of a solution.

properties (resistivity and relative permittivity) were calculated using Eqs. (1) and (3). The electrical properties of the deionized water mixed with 10 to $100 \mathrm{~cm}^{3}$ saline solution at various frequencies are presented in Fig. 3, and those of the deionized water mixed with 100 to $1000 \mathrm{~cm}^{3}$ saline solution are presented in Fig. 4 .

From the experimental results, the electrical properties of saline solution are considered. The resistance of the saline solution is observed to be constant in the frequency range under investigation $(100 \mathrm{~Hz}-100 \mathrm{MHz})$. The relative permittivity of the saline solution has a frequency-independent characteristic when measured in the frequency range from $10 \mathrm{kHz}$ order to $100 \mathrm{MHz}$. The relative permittivity decreases in the low-frequency range $(100 \mathrm{~Hz}$ to $10 \mathrm{kHz}$ order) owing to the polarization effect of ionic charge accumulated at the interface between the fluid and the metallic electrode. ${ }^{(19)}$ This effect results in the formation of a thin layer with a thickness of $\mathrm{nm}$ order from the electrode, and the layer is represented by a series contact impedance connecting the electrode and saline solution. This contact impedance will not have a significant effect in the case of the long resistors designed in this study. Therefore, saline solution still has very promising characteristics for the development of HV resistors.

\section{Current-limiting Resistor in HV Impulse Generator}

In this study, saline solution was used in various applications. The first was as part of a current-limiting resistor in an HV impulse generator. An HV impulse was generated to imitate the overvoltage caused by a switching operation or lightning. According to the IEC standard, ${ }^{(3)}$ there are two standard waveforms, i.e., a lightning impulse voltage (LIV) and a switching impulse voltage (SIV). For the LIV, the front time and time to half are 1.2 and $50 \mu \mathrm{s}$, respectively. For the SIV, the front time and time to half are 250 and $2500 \mu \mathrm{s}$, respectively. ${ }^{(5,20)}$

For HV impulse generation, the simple resistor and capacitor circuit in Fig. 5 are utilized. The circuit is composed of a charging capacitor $\left(\mathrm{C}_{\mathrm{S}}\right)$, a sparking gap (SG), a front resistor $\left(\mathrm{R}_{\mathrm{d}}\right)$, a tail resistor $\left(\mathrm{R}_{\mathrm{e}}\right)$, and a load capacitor (test object). The waveform parameters $\left(T_{1}\right.$ and $\left.T_{2}\right)$ are respectively controlled by adjusting the front and tail resistors. The peak voltage is controlled by the charging voltage across the charging capacitor. The sparking gap ensures an open circuit during the charging process and a short circuit when the charging voltage reaches the required voltage. ${ }^{(20,21)}$ 


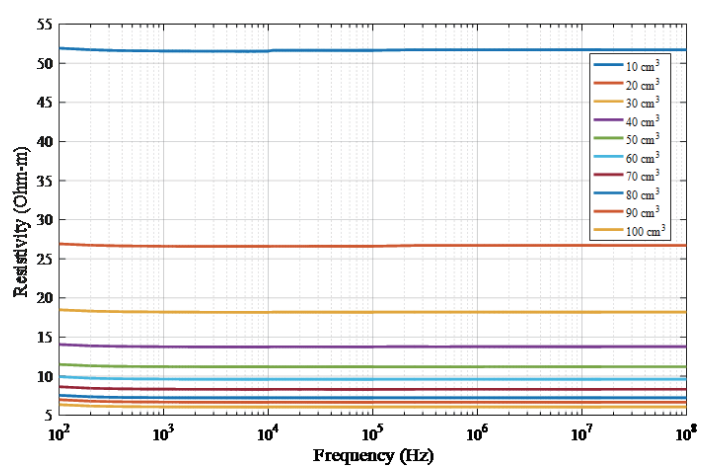

(a)

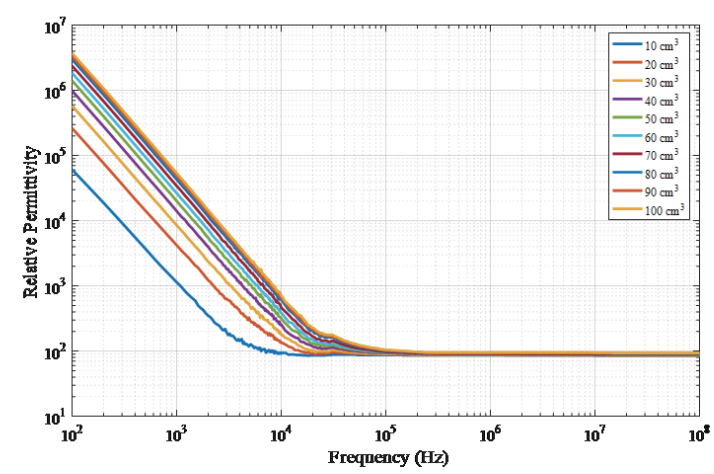

(b)

Fig. 3. (Color online) (a) Electrical resistivity and (b) relative permittivity of $100 \mathrm{~cm}^{3}$ deionized water mixed with 10 to $100 \mathrm{~cm}^{3}$ saline solution in the frequency range of $100 \mathrm{~Hz}$ to $100 \mathrm{MHz}$ obtained experimentally.

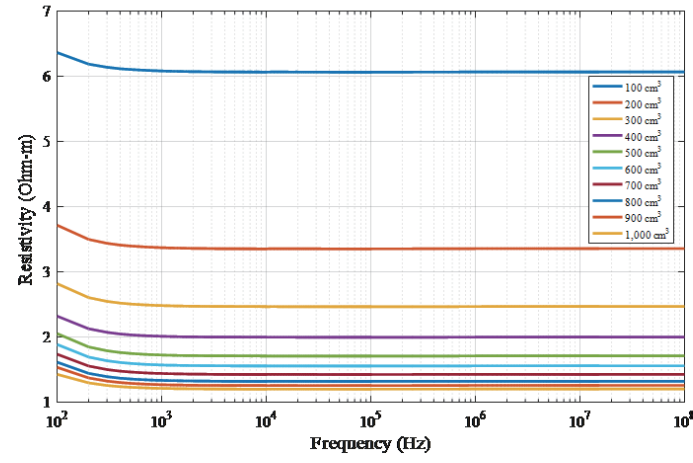

(a)

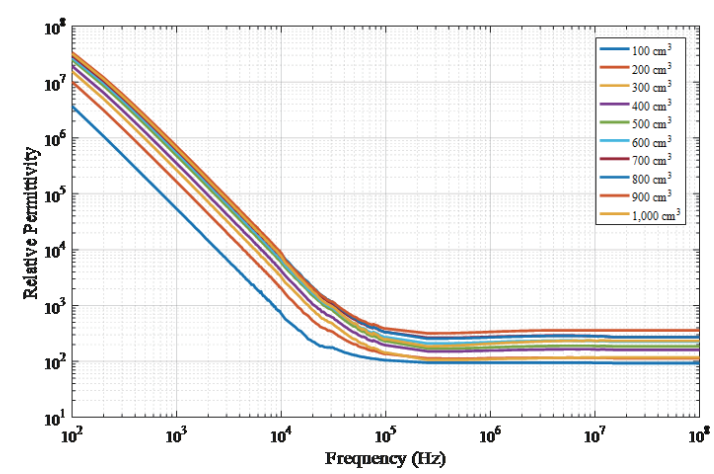

(b)

Fig. 4. (Color online) (a) Electrical resistivity and (b) relative permittivity of $1000 \mathrm{~cm}^{3}$ deionized water mixed with 100 to $1000 \mathrm{~cm}^{3}$ saline solution in the frequency range of $100 \mathrm{~Hz}$ to $100 \mathrm{MHz}$ obtained experimentally.

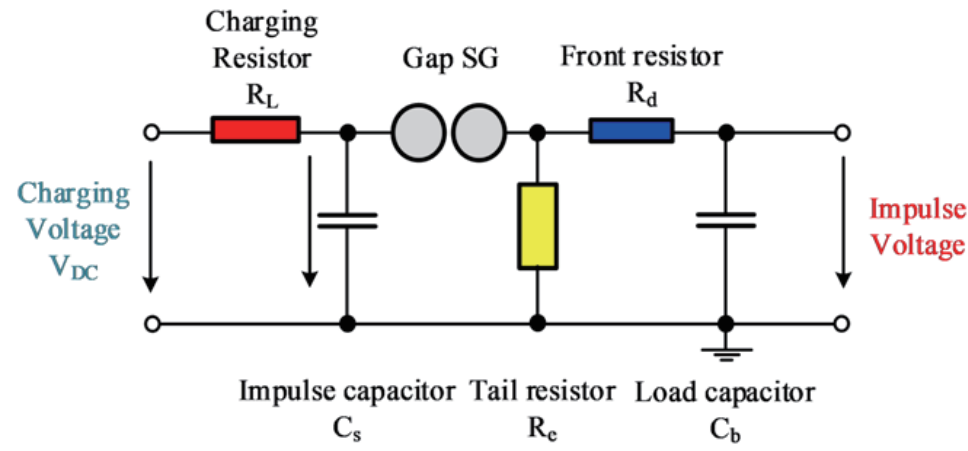

Fig. 5. (Color online) Basic equivalent circuit for impulse voltage generator.

All HV resistors can be constructed in an insulating enclosure with terminal electrodes as shown in Fig. 6. The enclosure is selected to be in the form of coaxial cylinders with available diameters. The saline solution is placed between the inner and outer cylinders. For better understanding, we should consider the case in which a current-limiting resistor $\left(\mathrm{R}_{\mathrm{L}}\right)$ is designed 


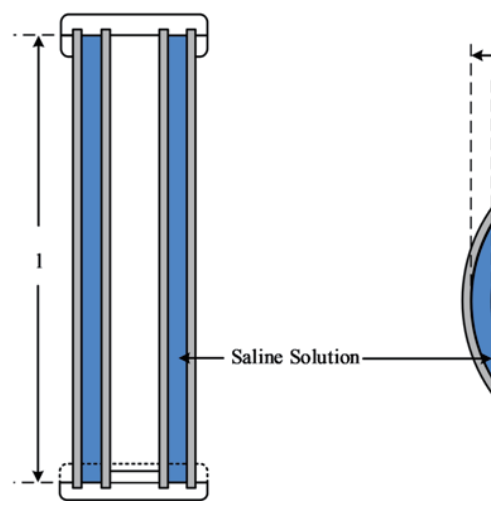

(a)

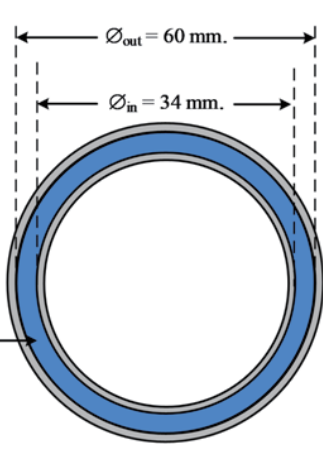

(b)

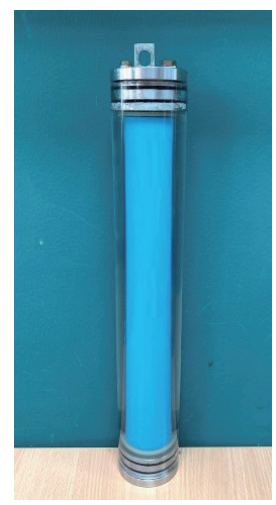

(c)

Fig. 6. (Color online) (a) Side and (b) top views of infrastructure of current-limiting resistor, and (c) developed current-limiting resistor.

as an example. The voltage and current ratings of the resistor were selected to be $100 \mathrm{kV}$ and $10 \mathrm{~A}$, respectively. The design procedure of the HV resistor started with the selection of the insulating enclosure length. The critical electric field strength (voltage per length) used in the design was $3 \mathrm{kV} / \mathrm{cm}$, so the designed enclosure length was $33 \mathrm{~cm}$, and for safety reasons, the length was selected to be $36 \mathrm{~cm}$. The inner and outer diameters were 34 and $60 \mathrm{~mm}$, respectively. From the selected rating, the resistor should have a resistance of $10 \mathrm{k} \Omega$. The resistivity of the saline solution was calculated using Eq. (1), and the calculated resistivity is expressed by

$$
\rho=\frac{10 \times 10^{3}\left(\pi\left(0.030^{2}-0.017^{2}\right)\right)}{0.36}=53 \Omega \cdot \mathrm{m} .
$$

From the calculated resistivity, the volume ratio of the normal saline and deionized water was selected from the results in Fig. 3(a). The resistivity $(\rho)$ was $53 \Omega \cdot \mathrm{m}$. From the designed parameters, the resistor was constructed as shown in Fig. 6. Such a resistor has also been well used as the current-limiting resistor in an HV impulse generator.

\section{Voltage Divider Based on Saline Solution}

The second application of saline solution was as part of an HV divider. For HV measurement, a voltage divider is generally used to reduce the signal voltage to an appropriate level that can be measured by an instrument such as a digital oscilloscope or a peak voltmeter. Normally, a capacitive voltage divider is used in the laboratory because it is easily designed and constructed. However, the stray capacitance and undesired inductance can make it difficult to use a capacitive voltage divider to measure voltages with a very short rise time (100 ns order). ${ }^{(22-25)}$ A resistive voltage divider is also used to measure voltages with a very short rise time. The time response of a resistive voltage divider mainly depends on the resistance of the voltage divider and the stray capacitance. Decreasing the volume of a voltage divider will decrease the stray capacitance and response time. ${ }^{(26,27)}$ 


\subsection{Design and construction of a voltage divider}

The design of the saline solution voltage divider is depicted in Fig. 7(a). The HV part of the developed divider comprises a coaxial cylindrical plastic tube filled with saline solution mixed with deionized water. The ends of the resistor are in contact with aluminum electrodes. The HV part has a thickness $\left(d_{H V}\right)$ of $0.5 \mathrm{~mm}$ and a height $\left(S_{H V}\right)$ of $990 \mathrm{~mm}$. There is a central aluminum plate connected to the low-voltage part of the voltage divider. The low-voltage part was constructed from a metal film resistor and connected to a cable connector for voltage measurement. The resistance of the HV part can be controlled by the resistivity of the saline solution mixture in deionized water. The resistance of the $\mathrm{HV}$ part was set to be $10 \mathrm{k} \Omega$. The low-voltage part was constructed from four $200 \Omega$ metal oxide resistors connected in parallel and enclosed in an aluminum housing. The HV part was connected to the low-voltage part and a coaxial cable of $50 \Omega$ characteristic impedance. At the receiving end of the cable, a $50 \Omega$ attenuator with a scale factor of 10 was connected to a digital oscilloscope. The equivalent circuit of the developed voltage divider is shown in Fig. 7(b). The structure of the saline solution voltage divider, the low-voltage part, and the attenuator are shown in Fig. 8.

\subsection{Electrical field stress control of the voltage divider}

For the designed HV resistor in Fig. 8(a), a high electrical field stress occurs at the top and bottom electrodes as shown in Fig. 9. Under HV application, electrical discharge occurs at the top and bottom electrodes, affecting the measured voltage waveform. Therefore, it is necessary to control the electrical field stress using grading rings. A computer simulation based on the finite element method was utilized to calculate the voltage distribution and electrical field stress in this paper. To reduce the electric field stress, grading rings were installed at the upper and lower parts of the HV resistor as shown in Fig. 10. The upper electrode was in the form of two rings having diameters of $65 \mathrm{~cm}$ with a distance between them of $25 \mathrm{~cm}$. The lower ring was installed $15 \mathrm{~cm}$ below the top of the HV resistor. The total height of the HV resistor was

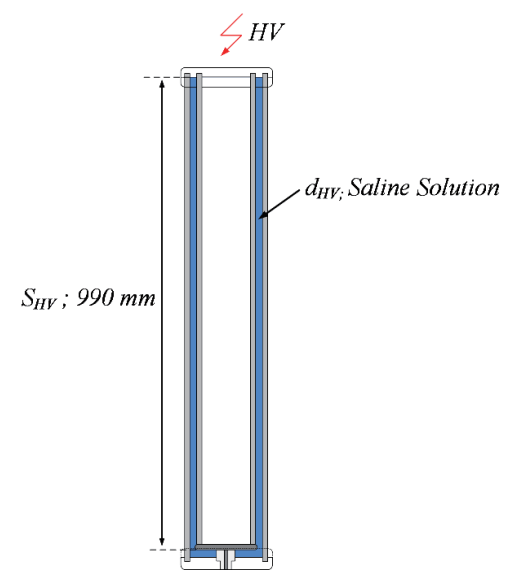

(a)

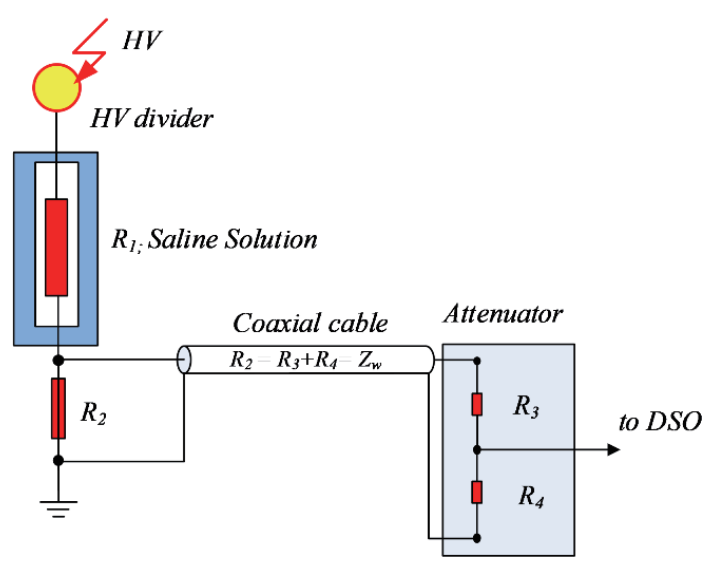

(b)

Fig. 7. (Color online) (a) Design of saline solution voltage divider and (b) equivalent circuit of measuring system. 


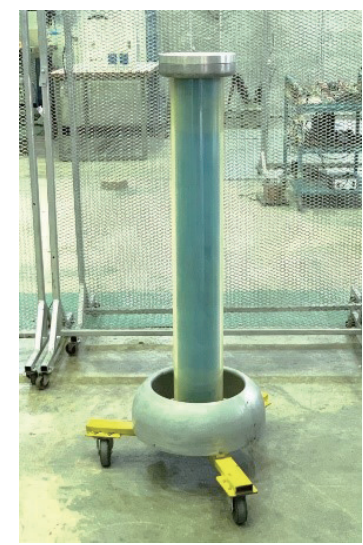

(a)

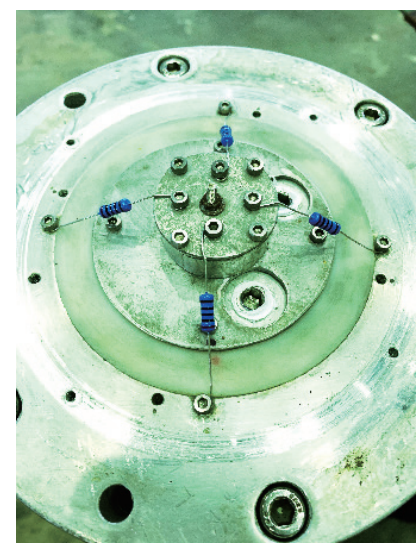

(b)

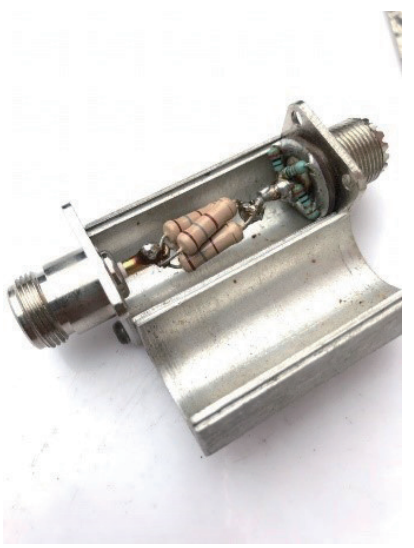

(c)

Fig. 8. (Color online) (a) Structure of saline solution voltage divider, (b) low-voltage part of saline solution voltage divider, and (c) attenuator constructed from metal film resistor in aluminum housing.
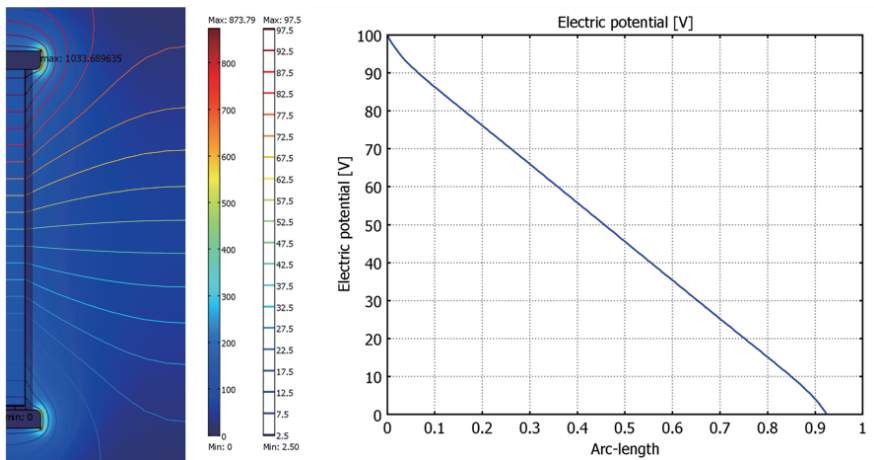

(a)

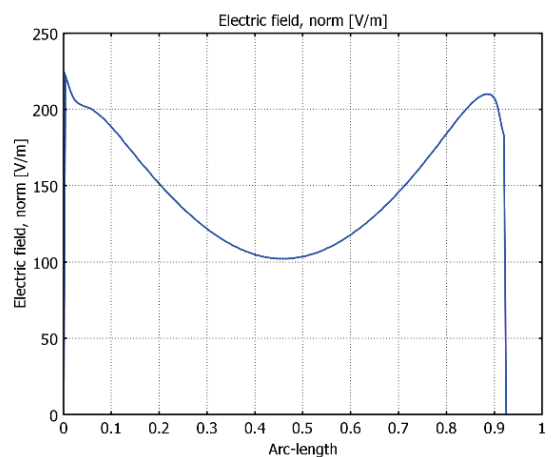

(b)

Fig. 9. (Color online) Test result of computer programming simulation of saline solution voltage divider without grading rings. (a) Electric field and (b) electric potential distributions.

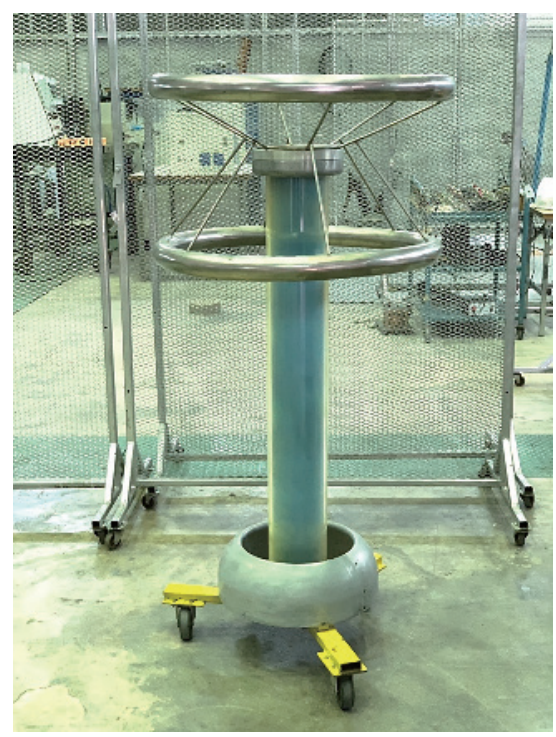

Fig. 10. (Color online) Developed saline solution voltage divider with grading rings. 
$100 \mathrm{~cm}$. With the appropriate locations and dimensions of the grading rings, the maximum electrical field stress was reduced as shown in Fig. 11.

\subsection{Unit step response test}

For the verification of the HV measuring system, international standards such as $\operatorname{IEC}^{(1,4,8)}$ and IEEE ${ }^{(28)}$ recommend that the parameters of the unit step response should correspond to the standard values. In particular, for a very fast transient voltage such as a chopped LIV, the measuring system should have a very fast response.

According to the IEC standard, ${ }^{(3)}$ there are two important indicators used to evaluate characteristics of an impulse-measuring system. These are the scale factor and the parameters of the unit step response. The scale factor of the measuring system should be approximately 1000 to 10000 to measure a voltage in the range of $\mathrm{kV}$ to MV. However, a voltage divider with a high scale factor is inappropriate since the induced interference voltage in the HV part can disturb the low-voltage part of the measuring system. For this reason, a voltage divider with an attenuator is used in the HV measuring system. ${ }^{(11,29-31)}$ In addition, the factors of the measuring system are not varied by more than $\pm 1 \%$ from the specified conditions and space clearance. The test circuit of the unit step response is depicted in Fig. 12(a) and the parameters

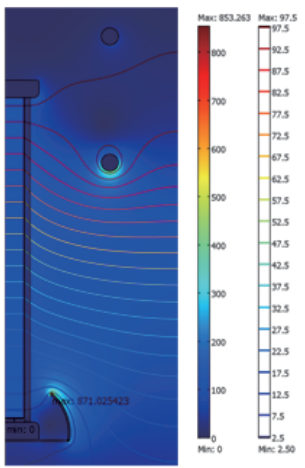

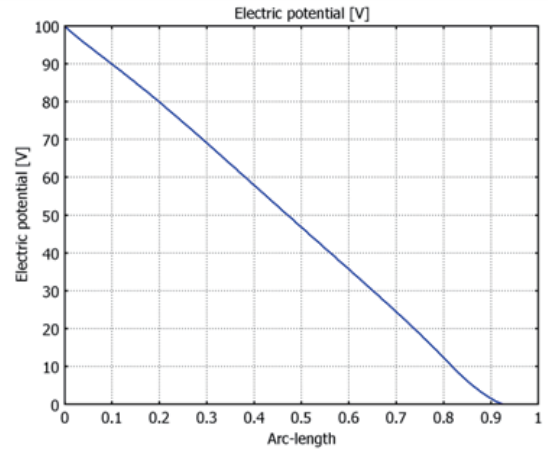

(a)

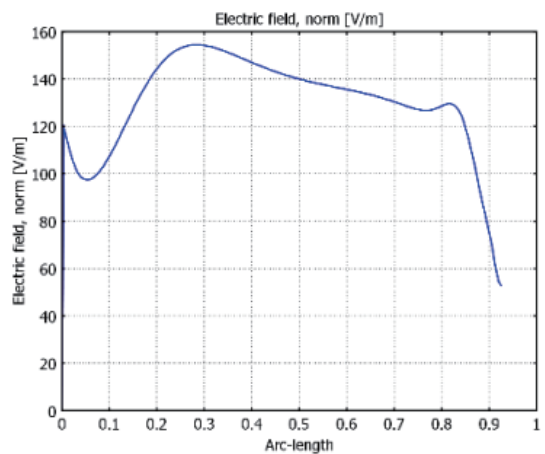

(b)

Fig. 11. (Color online) Test result of computer programming simulation of saline solution voltage divider with grading rings. (a) Electric field and (b) electric potential distributions.

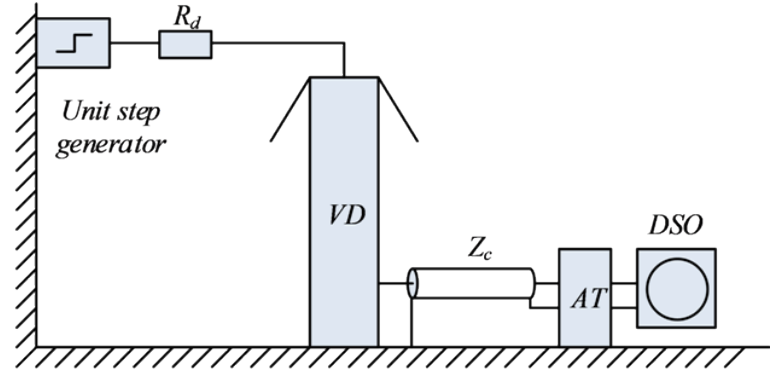

(a)

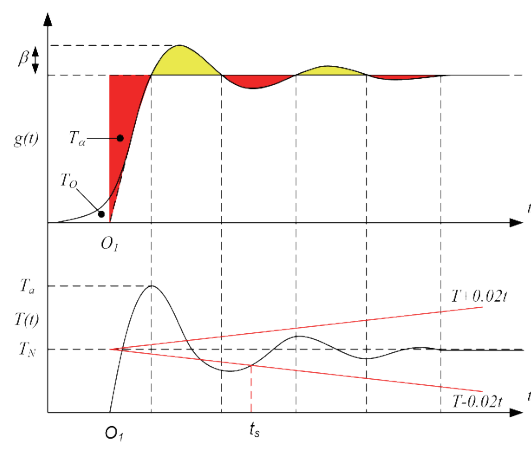

(b)

Fig. 12. (Color online) (a) Circuit for testing unit step response and (b) parameters of unit step response in accordance with IEC. ${ }^{(8)}$ 
of the unit step response are experimental response time $(\mathrm{TN})$, partial response time $\left(T_{\alpha}\right)$, settling time $\left(t_{s}\right)$, initial distortion time $\left(T_{0}\right)$, and overshoot $(\beta)$ as illustrated in Fig. 12(b). ${ }^{(8)}$ To verify the measuring system, the unit step response parameters are in the ranges recommended in the IEC standard. ${ }^{(3,8)}$

The recommendations in IEC $60060-2$ are separated into three parts. ${ }^{(8)}$ The first part is the measurement of full and tail-chopped LIVs. The second part is the measurement of frontchopped LIVs, and the third part is the measurement of the switching impulse. For a reference measuring system, the IEC standard has the recommended response parameters shown in Table 1.

In addition, IEC $61211^{(4)}$ (insulator puncture test in air) also recommended the response parameters of the measuring system for the steep-front impulse voltage reference shown in Table 2.

The unit step response tests of the divider with the saline solution were carried out by applying a standard unit step voltage generated by a unit step generator (GAUSS RIG1000H). A $500 \mathrm{MHz}$ digital oscilloscope was employed and connected with the developed measuring system in the test. The experimental setup for the unit step response test is shown in Fig. 13. The scale factor of the measuring system is 4250 . To determine the appropriate damping

Table 1

Recommended response parameters for impulse voltage reference of measuring system.

\begin{tabular}{lccc}
\hline Parameter & $\begin{array}{c}\text { Full and tail-chopped } \\
\text { lightning impulse }\end{array}$ & $\begin{array}{c}\text { Front-chopped } \\
\text { lightning impulse }\end{array}$ & Switching impulse \\
\hline Experimental response time $T_{N}$ & $\leq 15 \mathrm{~ns}$ & $\leq 10 \mathrm{~ns}$ & - \\
Settling time $t_{s}$ & $\leq 200 \mathrm{~ns}$ & $\leq 150 \mathrm{~ns}$ & $\leq 10 \mu \mathrm{s}$ \\
Partial response time $T_{\alpha}$ & $\leq 30 \mathrm{~ns}$ & $\leq 20 \mathrm{~ns}$ & - \\
\hline
\end{tabular}

Table 2

Recommended response parameters for steep-front impulse voltage reference of measuring system.

\begin{tabular}{lc}
\hline Parameter & $\begin{array}{c}\text { Front-chopped } \\
\text { lightning impulse }\end{array}$ \\
\hline Minimum sampling rate of digital recorders used in the test & $500 \mathrm{MS} / \mathrm{s}$ \\
Resolution of digital recorders used in the test & $8 \mathrm{bits}$ \\
Partial response time $T_{\alpha}$ & $\leq 3 \mathrm{~ns}$ \\
\hline
\end{tabular}

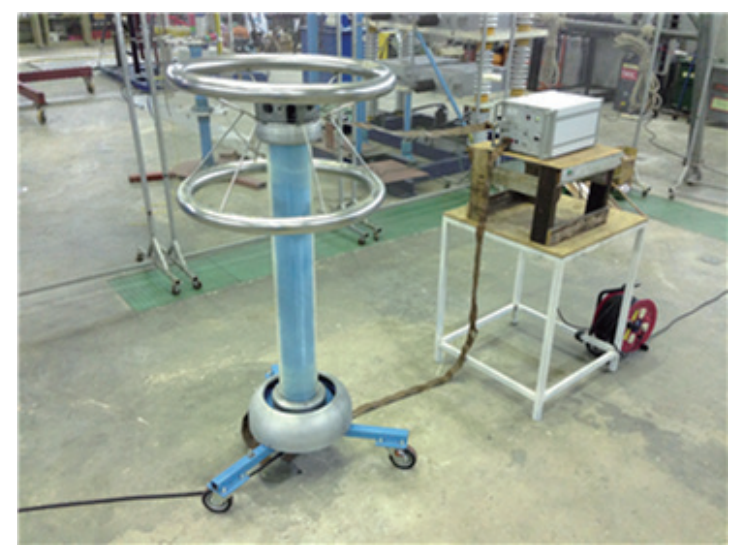

Fig. 13. (Color online) Experimental setup for unit step response test. 
resistance, experiments were carried out while adjusting the resistance from 0 to $500 \Omega$. It was found that the best response time is obtained for a resistance of $200 \Omega$.

The normalized unit step response $[g(t)]$ and the integral of the normalized unit step response obtained with the appropriate damping resistor are presented in Figs. 14(a) and 14(b), respectively. The time response parameters shown in Table 3, i.e., the partial response time $\left(T_{\alpha}\right)$ of $1.86 \mathrm{~ns}$, the experimental response time $\left(T_{N}\right)$ of $1.54 \mathrm{~ns}$, and the settling time $\left(t_{s}\right)$ of $42.80 \mathrm{~ns}$, are in accordance with the requirement in the standard for the measurement of full and frontchopped LIV waveforms. With the promising response parameters, the developed measuring system can also be used as a reference measuring system.

\subsection{LIV withstand test}

Generally, the equipment for measuring LIVs in an HV engineering laboratory uses a voltage divider. A LIV testing system can be separated into two parts. The first part generates an HV impulse and includes the impulse generator and test object. The second part is the voltagemeasuring system. This part includes the voltage divider, a damped resistor $\left(R_{d}\right)$, a coaxial cable, on attenuator, and a digital oscilloscope. A schematic of the LIV test is shown in Fig. 15.

A LIV withstand test was carried out to determine the insulation level. The test arrangement is shown in Fig. 16. It was found that the developed measuring system can pass a LIV withstand test at $330 \mathrm{kV}$ with withstand lightning impulse waveforms having both positive and negative polarities as shown in Fig. 17.

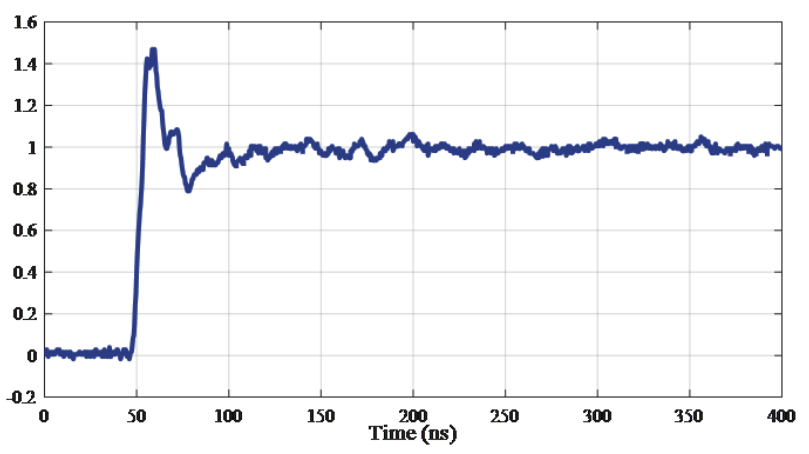

(a)

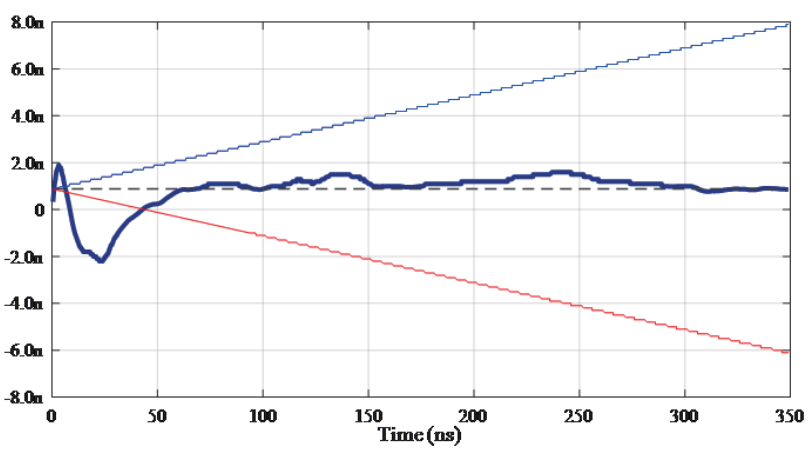

(b)

Fig. 14. (Color online) (a) Normalized unit step response and (b) integral of normalized unit step response of the developed measuring system.

Table 3

Unit step response parameters for developed measuring system.

\begin{tabular}{lr}
\hline Parameter & \\
\hline Experimental response time $T_{N}$ & $1.54 \mathrm{~ns}$ \\
Settling time $t_{s}$ & $42.80 \mathrm{~ns}$ \\
Partial response time $T_{\alpha}$ & $1.86 \mathrm{~ns}$ \\
\hline
\end{tabular}




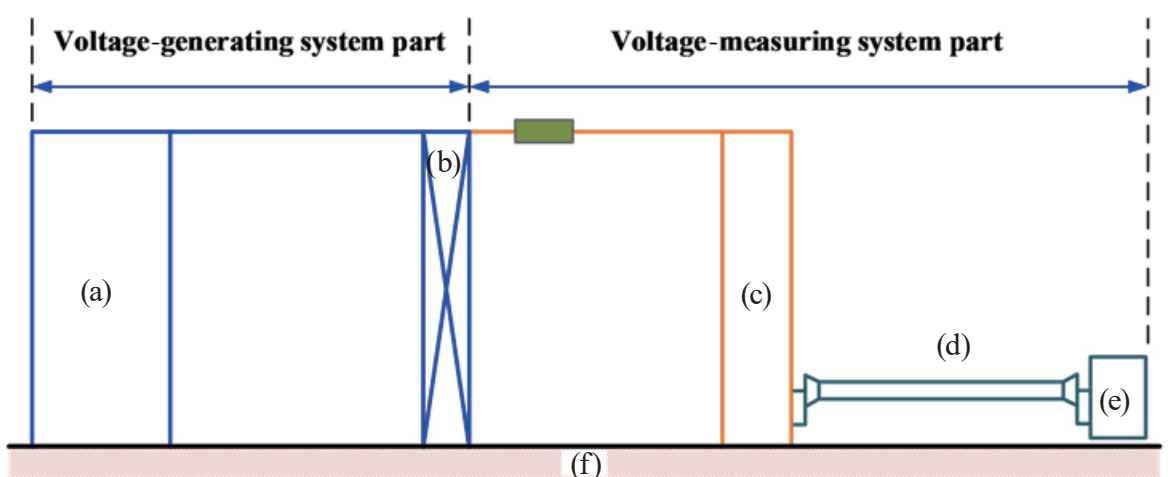

Fig. 15. (Color online) (a) Impulse generator, (b) test object, (c) voltage divider, (d) coaxial cable, (e) digital oscilloscope, and (f) ground of the LIV test circuit.

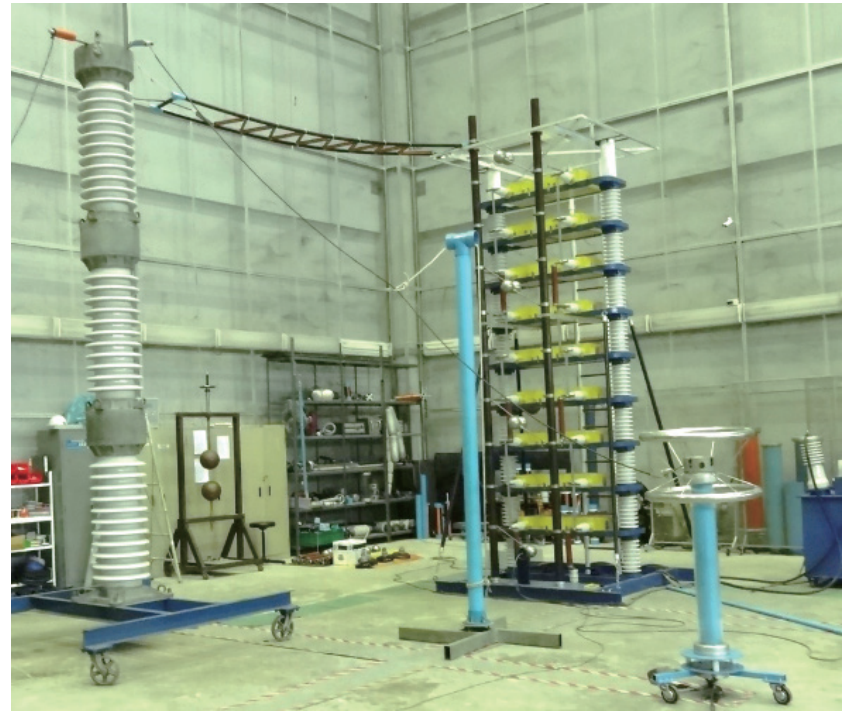

Fig. 16. (Color online) Arrangement of LIV withstand test.

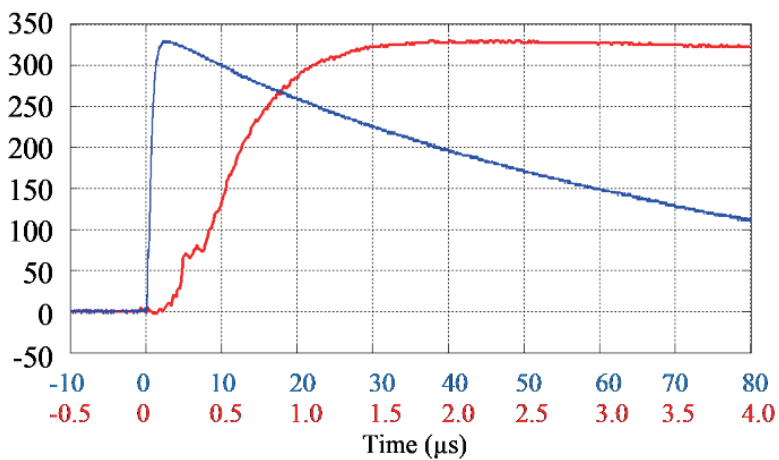

(a)

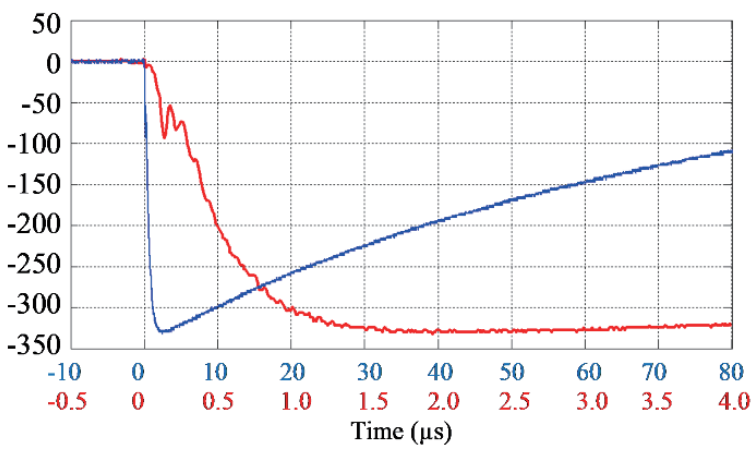

(b)

Fig. 17. (Color online) (a) Positive and (b) negative polarities of the withstand lightning impulse waveform measured by the saline solution voltage divider. 


\subsection{Measurement of steep-front impulse voltage}

To further verify the validity of the divider with saline solution, the capability of measuring a steep-front impulse voltage waveshape was determined. A steep-front impulse voltage is normally generated by a chopped wave impulse voltage. The equivalent circuit for the steepfront impulse voltage test is shown in Fig. 18. The test object is connected in series with a sparking gap. To generate the steep-front impulse voltage, a standard impulse voltage is generated across the gap and the test object. When the voltage across the gap reaches the controlled level, breakdown occurs at the gap. The applied voltage is suddenly generated across the test object and a steep-front impulse voltage is generated.

To confirm the performance of the developed measuring system in the measurement of a fast-rise-time impulse voltage or a steep-front impulse voltage, a voltage was generated across a suspension insulator. The developed measuring system was connected across the insulator. The experimental setup is shown in Fig. 19. The measured waveforms with positive and negative polarities in comparison with those from a conventional voltage-measuring system are shown in Fig. 20. Note that the conventional measuring system has the time parameters $T_{\alpha}=$ $9.8 \mathrm{~ns}, T_{N}=13.6 \mathrm{~ns}$, and $t_{s}=119 \mathrm{~ns}$ according to Table 1 , but they do not conform to the values

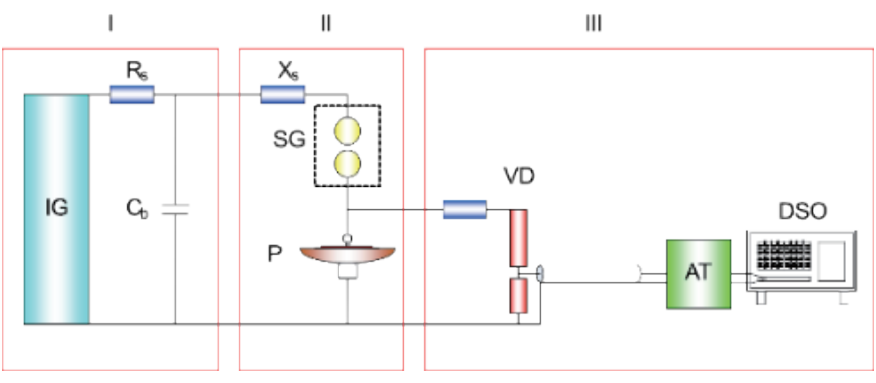

(a)

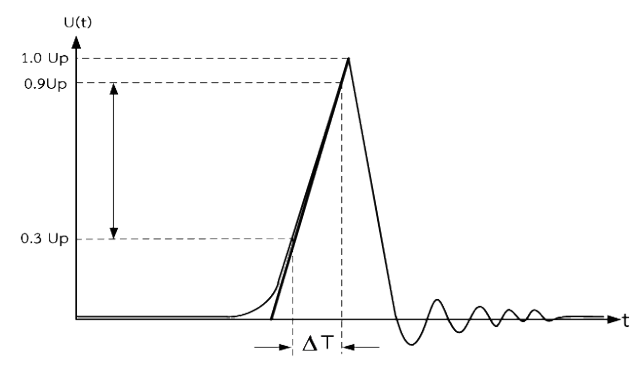

(b)

Fig. 18. (Color online) (a) Equivalent circuit of steep-front impulse voltage test and (b) standard waveform of steepfront impulse voltage.

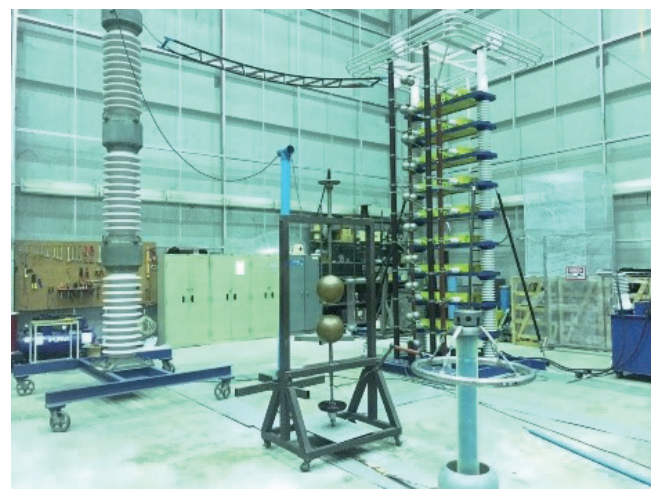

(a)

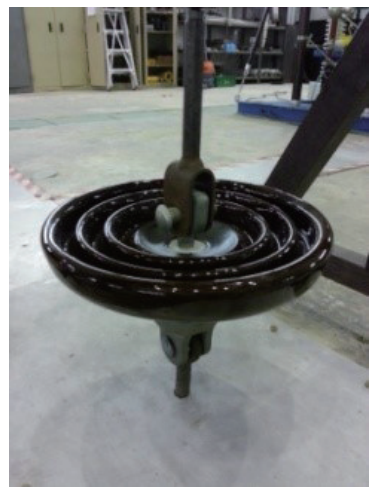

(b)

Fig. 19. (Color online) (a) Experimental setup for steep-front measuring system. (b) Holding the suspension insulator. 


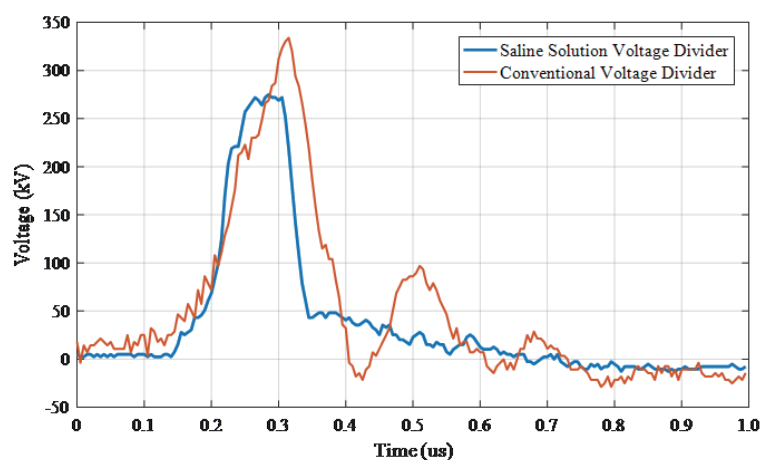

(a)

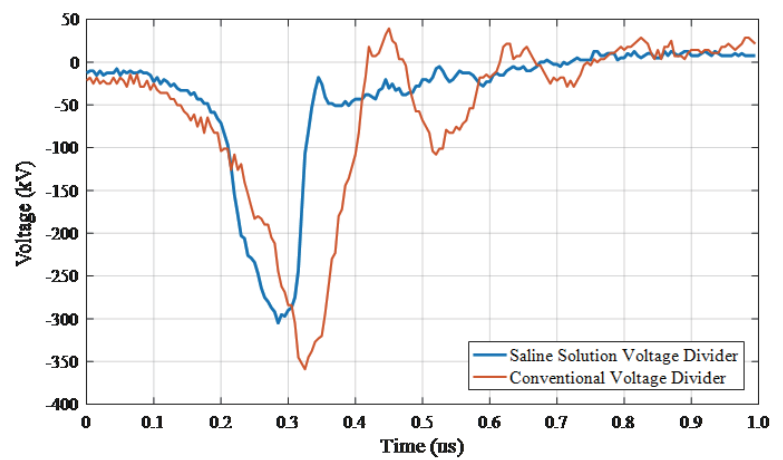

(b)

Fig. 20. (Color online) Steep-front impulse waveforms measured using the developed system and conventional voltage divider.

in Table 3, so the system is suitable for the measurement of a standard lightning voltage but not for the measurement of a steep-front impulse voltage. From the test results, the developed system can provide measured waveforms more rapidly than the conventional system, with the measured waveforms having no oscillation.

\section{Conclusions}

In this study, saline solution has been developed as a part in HV devices. Its first application was in a current-limiting resistor, and its other application was in an impulse voltage divider. To achieve the desired functions of the saline solution, the frequency dependence of the electrical properties of the saline solution, i.e., resistivity and relative permittivity, was studied. It was found that both the resistivity and relative permittivity of the saline solution have frequencydependent characteristics below a specific frequency. This is appropriate for the development of an HV generator and an impulse voltage-measuring system employing saline solution. The design and construction of a current-limiting resistor and a voltage divider with saline solution have been discussed. Results obtained from experiments in an HV laboratory such as the unit step response, impulse voltage measurements, and steep-front voltage measurements have shown the promising performance characteristics of saline solution in the two applications.

\section{Acknowledgments}

This work was supported by the Faculty of Engineering, King Mongkut's Institute of Technology Ladkrabang.

\section{References}

1 E. O. Aluyor and M. Ori-Jesu: Afr. J. Biotechnol. 8 (2009) 915.

2 T. Kovács, W. Feng, A. Totterdill, J. M. C. Plane, S. Dhomse, J. C. Gómez-Martín, G. P. Stiller, F. J. Haenel, C. Smith, P. M. Forster, R. R. García, D. R. Marsh, and M. P. Chipperfield: Atmos. Chem. Phys. 17 (2017) 883. https://doi.org/10.5194/acp-17-883-2017 
3 High-voltage test techniques - Part 1 General definitions and test requirements: International standard IEC 60060-1, 3rd ed. (Geneva, Switzerland, 2010).

4 Insulators of ceramic material or glass for overhead lines with a nominal voltage greater than $1000 \mathrm{~V}-$ Impulse puncture testing in air: International standard IEC 61211, 2nd ed. (Geneva, Switzerland, 2004).

5 K. Schon: High Impulse Voltage and Current Measurement Techniques (Springer, Berlin, 2013). https://doi. org/10.1007/978-3-319-00378-8

6 E. Onal, O. Kalenderli, and S. Seker: IEEE Trans. Dielectr. Electr. Insul. 15 (2008) 893. https://doi. org $/ 10.1063 / 1.4897477$

7 Z. Matyas and M. Aro: IEEE Trans. Instrum. Meas. 54 (2005) 2013. https://doi.org/10.1109/TIM.2005.853674

8 High-voltage test techniques - Part 2 Measuring systems: International standard IEC 60060-2, 3rd ed. (Geneva, Switzerland, 2010).

9 C. Melancon and G. R. Mitchel: Rev. Sci. Instrum. 58 (1987) 857. https://doi.org/10.1063/1.1139645

10 Information of High Voltage Resistor: https://file01.itaiwantrade.com/07eb2c64-1da6-46d5-98cf75c3df52287f/4d25b9ab-6d97-4fce-9592-de242f0de6d5_hv_resistor.pdf. (accessed 2019).

11 B. Racz and A. Patocs: Meas. Sci. Technol. 3 (1992) 926.

12 Y. Lui, F. Lin, G. Hu, and M. Zhang: IEEE Trans. Instrum. Meas. 60 (2011) 996. http://doi.org/10.1109/ TIM.2010.2064410

13 B. Paophan, S. Potivejkul, P. Chaisiri, and P. Yutthagowith: Proc. 10th Int. Conf. Electrical Engineering/ Electronics, Computer, Telecommunications and Information Technology (IEEE, 2013). http://doi.org/10.1109/ ECTICon.2013.6559580

14 Y. F. Ge, L. Li, Y. L. Liu, M. Li, and Q. Kang: Rev. Sci. Instrum. 85 (2014) 105106. https://doi. org $/ 10.1063 / 1.4897477$

15 W. Jia, W. Chen, C. Mao, and J. Zeng: Rev. Sci. Instrum. 81 (2010) 034703. https://doi.org/10.1063/1.3327823

16 Z. Y. Li: Rev. Sci. Instrum. 59 (1988) 1244.

17 Z. Y. Lee: Rev. Sci. Instrum. 54 (1983) 1060.

18 N. Pattanadech: Electrical Engineering Material - Part 1 Insulation and Insulation Material (KMITL, Bangkok, 2017).

19 A. Chandra and B. Bagchi: J. Chem. Phys. 112 (2000) 1876. https://doi.org/10.1063/1.480751

20 E. Kuffel, W. S. Zaengl, and J. Kuffel: High Voltage Engineering Fundamentals 2nd ed. (ButterworthHeinemann,Oxford, 2000).

21 W. Hauschild and E. Lemke: High-Voltage Test and Measuring Techniques (Springer, Berlin, 2014). https:// doi.org/10.1007/978-3-642-45352-6

22 S. Jayaram, X. Y. Xu, and J. D. Cross: IEEE Trans. Ind. Appl. 36 (2000) 920.

23 T. Hobejogi and J. Biela: Proc. IEEE Pulse Power Conf. (PPC), (IEEE, 2011) p. 313.

24 D. M. Barrett, S. R. Byron, E. A. Crawford, D. H. Ford, W. D. Kimura, and M. J. Kushner: Rev. Sci. Instrum. 56 (1985) 2111.

25 M. M. Brady and K. G. Dedrick: Rev. Sci. Instrum. 33 (1962) 44.

26 G. R. Mitchel and R. Malewski: Rev. Sci. Instrum. 58 (1987) 853.

27 F. Campisi, E. Rinaldi, G. Rizzi, and C. Valagussa: Proc. 11th Int. Symp. High Voltage Engineering (IET, 1999) 1.164.

28 IEEE Standard for High-Voltage Testing Techniques, IEEE Std. 4-2013 (New York, 2013).

29 D. G. Pellinen and I. Smith: Rev. Sci. Instrum. 43 (1972) 299.

30 D. G. Pellinen and M. S. Di Capua: Rev. Sci. Instrum. 51 (1980) 70.

31 W. He, H. Yin, A. D. R. Phelps, A. W. Cross, and S. N. Spark: Rev. Sci. Instrum. 72 (2001) 4266.

\section{About the Authors}

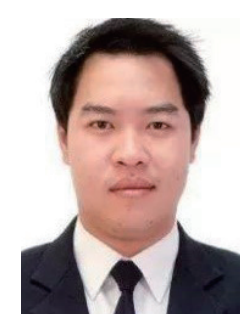

Punyavee Chaisiri received his B.Eng. and M.Eng. degrees from King Mongkut's Institute of Technology Ladkrabang (KMITL), Thailand, in 2008 and 2011, respectively. From 2012 to the present, he has been at KMITL, where he is a Ph.D. student in the Department of Electrical Engineering. His research interests are in high-voltage engineering applications and sensors.

(punyavee.ch@kmitl.ac.th) 


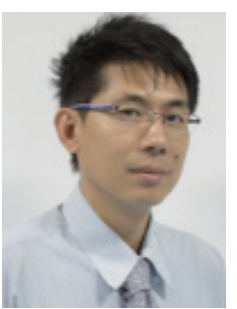

Peerawut Yutthagowith received his B.Eng. and M.Eng. degrees from Chulalongkorn University, Thailand, in 1998 and 2001, respectively, and his Ph.D. degree from Doshisha University, Japan, in 2010. From 2007 to the present, he has been at King Mongkut's Institute of Technology Ladkrabang. His research interests are in high-voltage engineering applications and sensors. (peerawut.yu@kmitl.ac.th) 